\title{
The Impressionists' bible
}

\section{Ogden Rood's textbook explaining the science of optics and colour mixing triggered an unexpectedly vivid response from the radical artists of the 1880s.}

\section{Martin Kemp}

The French Impressionist painters referred to the book Modern Chromatics: With Applications to Art and Industry as their "bible, and ... [they] carry it under their arm". So reported US painter Roland Rood to his father - the book's author - the distinguished physicist, Ogden Rood.

First published in 1879 by C. Kegan Paul and Company and translated into French as Théorie Scientifique des Couleurs in 1881, Ogden Rood's admired book intended to educate non-specialists in the latest optical research; in particular, the work of Hermann von Helmholtz on colour mixing. Ogden was himself an accomplished painter of watercolours, and saw it as his mission to teach artists about the science of colour.

According to correspondence collected in a 1906 article in The Scrip magazine, entitled Professor Rood's Theories of Color and Impressionism, Roland explained to his father that painters were paying special attention to "the oversensitivity of certain nerves of the eye to strong light, causing it to appear yellow; the dullness of certain nerves to weak light, making it bluish or purplish in tone; the principles of successive contrast, and more particularly of simultaneous contrast." $\mathrm{He}$ also explained their interest in the chapters on colour constants, on the duration of the impression on the retina, on colour mixture and on complementary colours.

Of these aspects of the perception of colour, Ogden's discussion of colour mixtures was perhaps most crucial to the Impressionist painters and their followers. Von Helmholtz established definitively the key distinction between the additive primaries (blue, red and green) for coloured lights and the subtractive primaries (blue, red and yellow) for pigment mixtures. Artists' theories on colour had previously failed to comprehend that light and pigments needed to be combined differently.

Ogden extended the experiments of physicist James Clerk Maxwell, who used spinning discs that mixed colours in different proportions. The disc mixtures were not additive because their variously coloured segments relied on the selective absorption of rays with different refractive properties. But they did suggest that painters might exploit optical mixtures on canvas rather than simply blending pigments on their palettes.

Ogden explained how different colours can be placed side by side - as lines or dots - and

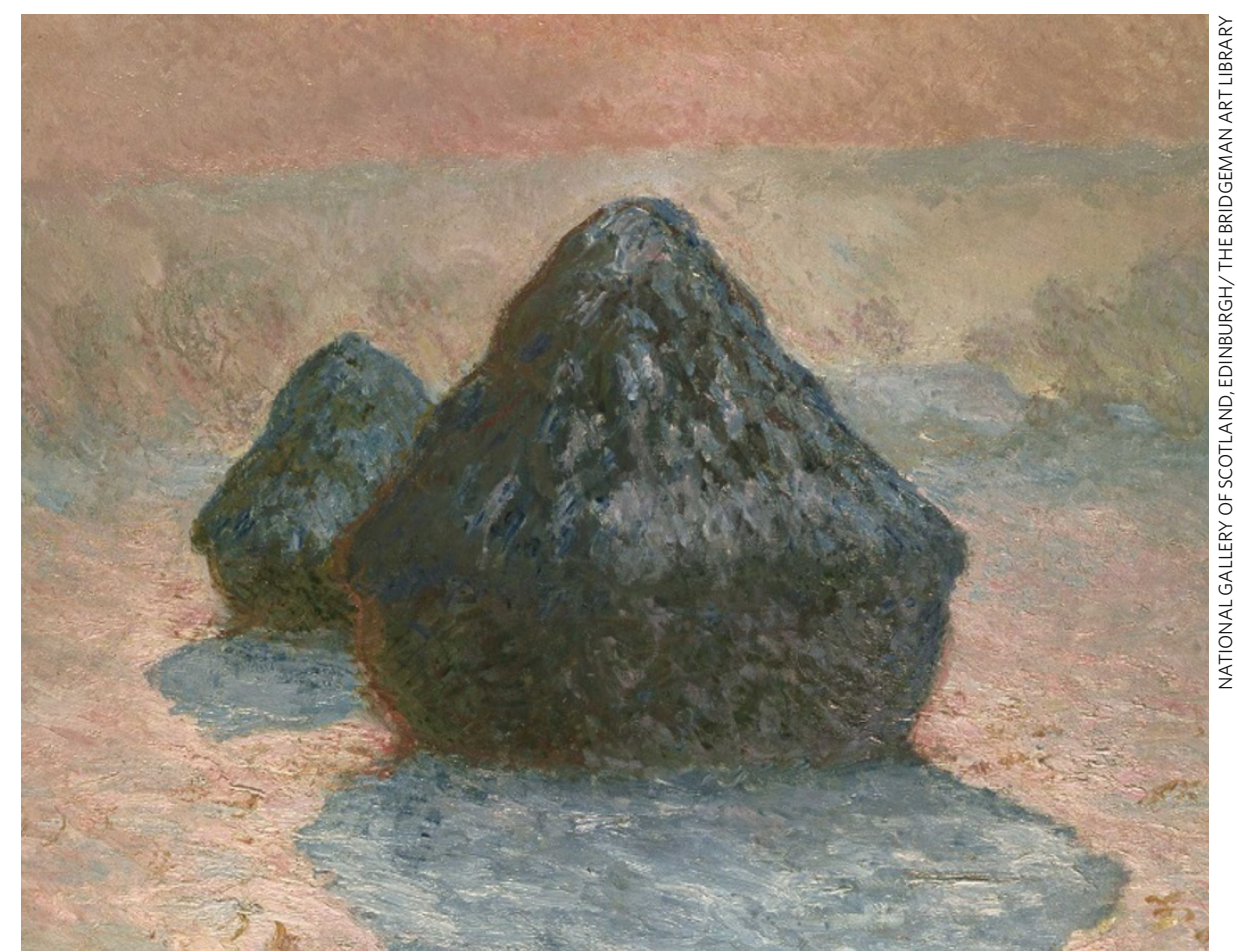

Claude Monet used Ogden Rood's techniques to produce subtle colour mixes in Haystacks: Snow Effect.

then viewed at a distance such that the blending is more or less accomplished by the eye of the beholder. Under these circumstances, the tints mix on the retina and produce new colours that are identical to those obtained by the method of spinning discs.

The divided brushstrokes of Impressionism preceded the publication of Ogden's book, but in the later 1880s it became fashionable to seek a more scientific method of painting based on 'décompositions prismatiques' (the splitting of white light into the seven primaries identified by Isaac Newton). The divisionist or Pointillist painters, led by Georges Seurat, come most readily to mind. But some of the mainstream Impressionists also took note.

Claude Monet, in particular, began to show a more serious attitude to his analysis of colour. His famous series paintings, such as the Haystacks from 1891, reflect this new emphasis, systematically exploring the varied symphonies of colour that played across the same view at different times of day and during different seasons.

The painting that explores the 'snow effect' (one of more than 30 pictures of haystacks painted by Monet) blazes with complementary colours, above all orange and cyan blue. Colours at the 'cold' end of the spectrum dominate. The complementaries were apparently applied in the studio, late in the execution of each piece and in a calculated manner.

At first sight, it seems that Ogden's impact on leading French painters met his fondest hopes. The reality was different, however. In their correspondence in The Scrip, Ogden responded gloomily to his son when asked about paintings by the "Frenchmen who call themselves Impressionists; some are by a fellow called Monet, others by a fellow called [Camille] Pissarro, and a lot of others".

"What do you think of them?", Roland ventured. "Awful! Awful!", Ogden gasped, horrified by the radical nature of the paintings.

When Roland told him what these painters said of his theories, Ogden became upset. He threw up his hands in horror and indignation, and cried: "If that is all I have done for art, I wish I had never written that book! My son, I always knew that a painter could see anything he wanted to in nature, but I never before knew that he could see anything he chose in a book."

As many educators have discovered, the results of arousing interest and propagating knowledge are not always what was expected. Monet's glorious Haystacks series demonstrates that this may not necessarily be a bad thing. Martin Kemp is research professor in the history of art at the University of Oxford, OX11PT, UK. 